\title{
Basic Amino Acid Inhibition of Cell Division and Macromolecular Synthesis in Saccharomyces cerevisiae
}

\author{
By ROBERTA SUMRADA AND TERRANCE G. COOPER \\ Department of Biological Sciences, University of Pittsburgh, Pittsburgh, \\ Pennsylvania 15260, U.S.A.
}

(Received 14 February 1978)

\begin{abstract}
Growth of Saccharomyces cerevisiae on poor nitrogen sources such as allantoin or proline was totally inhibited by addition of a non-degradable basic amino acid to the medium. Cells treated with lysine contained greatly reduced quantities of histidine and arginine. Conversely, lysine and histidine were severely reduced in arginase-deficient cells treated with arginine. When all three basic amino acids were present in the culture medium, growth was normal suggesting that synthesis of all three basic amino acids was decreased by an excess of any one of them. Inhibition of growth was accompanied by a fivefold increase in the observed ratio of budded to unbudded cells. These morphological changes suggested that DNA synthesis was inhibited. Consistent with this suggestion, addition of a basic amino acid to the culture medium substantially reduced the ability of the cells to incorporate $\left[{ }^{14} \mathrm{C}\right]$ uracil into alkali-resistant, trichloroacetic acid-precipitable material. RNA and protein synthesis, although decreased, were less sensitive to the effects of such additions.
\end{abstract}

\section{INTRODUCTION}

Addition of basic amino acids to the growth medium of fungi and yeast has been reported by several investigators to inhibit growth. Davis et al. (1970) observed that adding arginine to an arginase-defective mutant culture of Neurospora stopped its growth. Since the inhibition was relieved by supplying putrescine in the culture medium, they attributed the effects to feedback inhibition of ornithine biosynthesis by arginine. This in turn prevented formation of putrescine and thus starved the cells for polyamines. In another mould, Aspergillus nidulans, Pontecorvo et al. (1953) reported that exogenously supplied lysine inhibited growth of arginine auxotrophs and, vice versa, that addition of arginine inhibited growth of lysine auxotrophs. Hunter \& Downs (1945) noted that lysine competitively inhibited arginase and Meister (1965) suggested this as an explanation for the lysine-arginine antagonism. Cybis \& Weglenski (1969) argued more convincingly that competition of lysine and arginine for the basic amino acid permease was the reason for the lysine inhibition originally observed by Pontecorvo (1952) and Pontecorvo et al. (1953). The first reports of basic amino acid inhibition in yeast were made by Bourgeois (1969) and Bourgeois \& Thouvenot (1970). They observed that addition of 5 mM-lysine to the growth medium prevented post-exponential growth of Saccharomyces cerevisiae. Concurrent with growth inhibition, they observed a decrease of intracellular arginine and four to sixfold increases in arginase and ornithine transaminase activities. Since both wild-type and arginasedeficient strains were equally inhibited, they suggested that growth inhibition resulted from arginine starvation rather than lysine activation of arginine catabolism. This view was supported by their demonstration that lysine, added to the growth medium of an arginine auxotroph, inhibited growth when the medium was supplemented with a low concentration of arginine, but did not do so when the concentration of arginine was increased to $0.6 \mathrm{~mm}$. 
More recently, we found that growth may be inhibited by a variety of basic amino acids cther than lysine and under conditions where arginine was known to be present within the cell at high concentrations (Sumrada \& Cooper, 1976). These observations and the severe problems encountered when mutant strains must be grown on poor nitrogen sources in the presence of a basic amino acid (for example, during genetic mapping experiments of the linked dall, dal 2 and $l y s 1$ loci) prompted us to investigate the effects of basic amino acids on growth and macromolecular synthesis in an effort to identify those processes that are inhibited and the reasons for the inhibition.

\section{METHODS}

Strains. Wild-type strain м25 is a prototrophic diploid organism prepared as described earlier (Whitney \& Cooper, 1972). Strain M399 is a diploid organism carrying a mutation of the car 2 locus in homozygous condition. The haploid organisms used to construct this strain were selected on the basis of their inability to use ornithine as sole nitrogen source; growth on proline was normal. The cells were shown to be devoid of ornithine transaminase activity using the method of Jenkins \& Tsai (1970). Strain M58 is a diploid organism defective in the arginine catabolic enzyme arginase (Whitney \& Magasanik, 1973).

Culture conditions. The medium used was that of Wickerham (1946). In one experiment, lactate/ammonia medium was used which differed from that of Wickerham in that sodium lactate $\left(40 \mathrm{~g} \mathrm{l}^{-1}\right)$ was used in place of glucose and a supplement solution $\left(20 \mathrm{ml} \mathrm{l}^{-1}\right)$ was also added. This solution contained $25 \mathrm{ml}$ Tween 80 , $10 \mathrm{mg}$ ergosterol and $5 \mathrm{ml}$ ethanol. Whenever basic amino acids were added, only the L-isomers were used. Except where indicated, glucose $(0.6 \% \mathrm{w} / \mathrm{v})$ was used as sole carbon source. Nitrogen sources, except for urea and ureidoglycollate, were present at final concentrations of $0.1 \%(\mathrm{w} / \mathrm{v})$. All cultures were maintained at $30^{\circ} \mathrm{C}$.

Cell density measurements. Turbidimetric measurements of cell density were made using a Klett-Summerson colorimeter ( 500 to $570 \mathrm{~nm}$ bandpass filter). One hundred Klett units were approximately equivalent to $3 \times 10^{7}$ cells per ml culture. Visual determinations of cell numbers and the ratios of budded to unbudded cells were done using a Petroff-Hauser counting chamber. Samples removed for counting were fixed by adding an equal volume of solution containing $0.15 \mathrm{M}-\mathrm{NaCl}$ and $3.7 \%(\mathrm{v} / \mathrm{v})$ formaldehyde. Cell aggregates were broken up by vigorous vortexing and by repeatedly drawing the solution into a Pasteur pipette and forceably expelling it. This procedure was used in preference to sonication which caused some cell damage. However, we quantitatively compared ratios obtained by both methods and found no significant differences between them. For each value reported, 500 to 900 cells were counted. To eliminate subjective judgements concerning the point at which a budded cell was considered as two cells, budded cells were considered as single cells regardless of the bud size. Cell counts were completed within $48 \mathrm{~h}$; after this time cells appeared to be more fragile with age.

Assay of macromolecular synthesis. Protein synthesis was measured by incorporation of $\left[{ }^{3} \mathrm{H}\right]$ leucine into hot trichloroacetic acid-precipitable material Cultures were incubated with $15 \mu \mathrm{g}\left[{ }^{3} \mathrm{H}\right] l$ leucine $\mathrm{ml}^{-1}$ (specific activity, $87 \mu \mathrm{Ci} \mu \mathrm{mol}^{-1}$ ). At the times indicated, $0.2 \mathrm{ml}$ samples were removed from the culture and transferred to cold test tubes, followed immediately by addition of $4 \mathrm{ml}$ ice-cold $10 \%(\mathrm{w} / \mathrm{v})$ trichloroacetic acid (TCA) containing $1 \mathrm{mg}$ non-radioactive leucine $\mathrm{ml}^{-1}$. The samples were covered with marbles and placed in a boiling water bath for 15 to $20 \mathrm{~min}$. Precipitated protein was collected on nitrocellulose filters $(0.45 \mu \mathrm{m}$ pore diameters) and washed five times with $4 \mathrm{ml}$ cold $5 \%$ TCA. Filters were dried for at least $1 \mathrm{~h} \mathrm{at} 80^{\circ} \mathrm{C}$ to remove all traces of TCA and the radioactivity was determined using a standard toluene scintillation fluid.

RNA synthesis was measured by incorporation of $\left[{ }^{3} \mathrm{H}\right]$ uracil into cold TCA-precipitable material. Cultures were incubated with $\left.25 \mu \mathrm{g} \mathrm{[}{ }^{3} \mathrm{H}\right] \mathrm{uracil} \mathrm{m}{ }^{-1}$ (specific activity $45 \mu \mathrm{Ci} \mu \mathrm{mol}^{-1}$ ). At the times indicated, $0 \cdot 2 \mathrm{ml}$ samples were transferred to cold test tubes, followed immediately by addition of $5 \mathrm{ml} 10 \%$ TCA containing $1 \mathrm{mg}$ non-radioactive uracil $\mathrm{ml}^{-1}$. Subsequently the samples were treated as described for the assay of protein except that heating was omitted.

DNA synthesis was measured by incorporation of $\left[2-{ }^{14} \mathrm{C}\right]$ uracil into base-stable, TCA-precipitable material, essentially using the procedures of Hartwell (1970). Cultures were incubated with $8 \mu \mathrm{g}\left[2-{ }^{14} \mathrm{C}\right]$ uracil $\mathrm{ml}^{-1}$ (specific activity, $11 \mu \mathrm{Ci} \mu \mathrm{mol}^{-1}$ ). At the times indicated, $1 \mathrm{ml}$ samples were transferred to test tubes containing $1 \mathrm{ml} 2 \mathrm{M}-\mathrm{NaOH}$ and incubated at room temperature for 1 to $3 \mathrm{~d}$. Samples were then cooled and $100 \mu \mathrm{g}$ carrier DNA was added followed by $1 \mathrm{ml} 50 \%$ TCA. Filters were processed as described for the assay of RNA except that they were washed 10 times with $2 \mathrm{ml} 5 \%$ TCA.

Phase contrast photomicrography. Cell morphology was observed through a Zeiss microscope equipped with a na 1.0 planapochromatic $40 \times$ phase objective. Observations were recorded on Kodak $35 \mathrm{~mm}$ high contrast copy film developed in Kodak D-19 developer. 
Table 1. Doubling times (min) of wild-type (M25) and car2 mutant (M399) strains of S. cerevisiae growing on various nitrogen sources in the presence or absence of basic amino acids

Strains M 25 and M 399 were grown in minimal glucose medium with various nitrogen sources at final concentrations of $0.1 \%$ (urea and ureidoglycollate were used at $10 \mathrm{~mm}$ ). L-Lysine or L-ornithine were present at final concentrations of 1.75 and $4.7 \mathrm{~mm}$, respectively.

\begin{tabular}{lccccccc} 
Nitrogen source & \multicolumn{3}{c}{ Wild type } & \multicolumn{3}{c}{ car2 mutant } \\
& $\begin{array}{c}\text { No } \\
\text { addition }\end{array}$ & $\begin{array}{c}\text { Plus } \\
\text { lysine }\end{array}$ & $\begin{array}{c}\text { Plus } \\
\text { ornithine }\end{array}$ & & $\begin{array}{c}\text { No } \\
\text { addition }\end{array}$ & $\begin{array}{c}\text { Plus } \\
\text { lysine }\end{array}$ & $\begin{array}{c}\text { Plus } \\
\text { ornithine }\end{array}$ \\
Ummonia & 120 & 115 & 125 & & 160 & 190 & 230 \\
Allantoin & 160 & 150 & 170 & 160 & NG & NG \\
Ureidoglycollate & 175 & NG & - & 170 & NG & NG \\
Proline & 170 & 650 & NG & 205 & NG & NG \\
Citrulline & 200 & NG & 320 & 250 & NG & NG \\
Arginine & 290 & - & 195 & - & - & - \\
Serine & 150 & 155 & 140 & 512 & NG & NG \\
Alanine & 130 & 130 & 130 & 145 & 170 & 160 \\
Asparagine & - & - & - & 155 & - & 155 \\
Glutamate & 120 & 115 & 120 & - & - & - \\
Aspartate & - & - & - & 150 & 390 & NG \\
Ornithine & - & - & 165 & - & 185 & - & 215
\end{tabular}

NG, No growth after $48 \mathrm{~h} ;-$, not determined.

Isolation of intracellular amino acids and polyamines. Intracellular metabolites were isolated from both wild-type and mutant strains. Cells were grown to a density of $15 \mathrm{Klett}$ units in glucose/allantoin medium and divided into two portions. A basic amino acid was added to one portion while the other received no further additions. After $6 \mathrm{~h}$ incubation, both cultures were harvested by filtration, washed with a solution containing $0.9 \%(\mathrm{w} / \mathrm{v}) \mathrm{NaCl}$, resuspended in $5 \mathrm{ml} 5 \%$ TCA and incubated on ice for $1 \mathrm{~h}$. Cell debris and precipitated material were removed by centrifugation and extracted again with $3 \mathrm{ml} 5 \%$ TCA. The two supernatant solutions were combined and extracted three times with equal volumes of diethyl ether to remove TCA. The aqueous layer was heated to $60^{\circ} \mathrm{C}$ for $20 \mathrm{~min}$ to remove all traces of ether and then lyophilized. The material so obtained was used for isolation and analysis of the basic amino acids and polyamines. Basic amino acid pools were analysed using the short column of a Beckman model 120 amino acid analyser. Polyamine pools were analysed using the methods of Morris et al. (1969).

\section{RESULTS}

\section{Inhibition of growth by basic amino acids}

Our first objective was to determine which nitrogen sources would not support growth of $S$. cerevisiae in the presence of a non-degradable basic amino acid. Lysine increased the doubling times of the wild-type strain growing on any of the poor nitrogen sources tested, but apparently did not adversely affect growth on more readily used compounds such as ammonia or asparagine (Table 1). Addition of a basic amino acid that could be catabolized (ornithine) affected growth only on the poorest nitrogen sources, proline and ureidoglycollate. In the latter case we have shown (Sumrada et al., 1976) that the nitrogen source is urea derived from slow decomposition of ureidoglycollate.

With an ornithine transaminase-deficient (car2) strain, ornithine slowed growth on arginine, ammonia, aspartate and glutamate (Table 1). Growth of the car2 mutant strain with arginine as sole nitrogen source was also inhibited several fold compared with wildtype organisms.

As little as $0 \cdot 1 \mathrm{~mm}$-lysine totally prevented growth of the wild type in glucose/allantoin medium while 0.25 mm-ornithine increased the doubling time of a car 2 mutant strain twofold when allantoin was used as nitrogen source. 
Table 2. Intracellular basic amino acids in wild-type (м25) and mutant (м58, м399) strains of $S$. cerevisiae

The strains were grown in minimal glucose medium containing the indicated nitrogen source to a density of approximately 15 Klett units. Each culture was then divided and one half received basic amino acids (lysine or arginine at $2.5 \mathrm{~mm}$ and histidine at $0.5 \mathrm{~mm}$ final concentrations) while the other half remained untreated. After 6 to $10 \mathrm{~h}$ incubation (or until the control culture reached a density of approximately 80 Klett units), the cells were harvested and their basic amino acids were analysed. Culture volumes ranged from 237 to $258 \mathrm{ml}$ and these variations were accounted for in the normalization of the data.

\begin{tabular}{|c|c|c|c|c|c|c|c|c|}
\hline \multirow[b]{2}{*}{ Strain } & \multirow[b]{2}{*}{ Medium } & \multirow{2}{*}{$\begin{array}{c}\text { Cell } \\
\text { density } \\
\text { (Klett } \\
\text { units) }\end{array}$} & \multicolumn{3}{|c|}{$\begin{array}{l}\text { Basic amino acids in total } \\
\text { cell sample }(\mu \mathrm{mol})\end{array}$} & \multicolumn{3}{|c|}{$\begin{array}{l}\begin{array}{c}\text { Relative level of basic } \\
\text { amino acids* }\end{array} \\
\text {. }\end{array}$} \\
\hline & & & Lysine & $\begin{array}{l}\text { Histi- } \\
\text { dine }\end{array}$ & Arginine & Lysine & $\begin{array}{l}\text { Histi- } \\
\text { dine }\end{array}$ & Arginine \\
\hline M 25 & $\begin{array}{l}\text { Ammonia } \\
\text { Ammonia + lysine }\end{array}$ & $\begin{array}{l}70 \\
75\end{array}$ & $\begin{array}{r}7 \cdot 63 \\
67 \cdot 92\end{array}$ & $\begin{array}{l}0 \cdot 64 \\
0 \cdot 10\end{array}$ & $\begin{array}{l}7 \cdot 70 \\
0 \cdot 57\end{array}$ & $\begin{array}{l}1 \cdot 00 \\
8 \cdot 77\end{array}$ & $\begin{array}{l}1 \cdot 00 \\
0 \cdot 15\end{array}$ & $\begin{array}{l}1.00 \\
0.07\end{array}$ \\
\hline M 25 & $\begin{array}{l}\text { Asparagine } \\
\text { Asparagine +lysine }\end{array}$ & $\begin{array}{l}75 \\
90\end{array}$ & $\begin{array}{r}9 \cdot 80 \\
24 \cdot 40\end{array}$ & $\begin{array}{l}0 \cdot 28 \\
0 \cdot 27\end{array}$ & $\begin{array}{l}9 \cdot 92 \\
8 \cdot 40\end{array}$ & $\begin{array}{l}1 \cdot 29 \\
2 \cdot 65\end{array}$ & $\begin{array}{l}0 \cdot 44 \\
0 \cdot 34\end{array}$ & $\begin{array}{l}1 \cdot 30 \\
0 \cdot 90\end{array}$ \\
\hline M25 & $\begin{array}{l}\text { Urea } \\
\text { Urea +lysine }\end{array}$ & $\begin{array}{l}70 \\
75\end{array}$ & $\begin{array}{l}10 \cdot 58 \\
82 \cdot 08\end{array}$ & $\begin{array}{l}0.47 \\
0.07\end{array}$ & $\begin{array}{r}11 \cdot 55 \\
1.53\end{array}$ & $\begin{array}{r}1 \cdot 54 \\
10 \cdot 72\end{array}$ & $\begin{array}{l}0 \cdot 82 \\
0 \cdot 11\end{array}$ & $\begin{array}{l}1.67 \\
0 \cdot 20\end{array}$ \\
\hline M25 & $\begin{array}{l}\text { Allantoin } \\
\text { Allantoin + lysine }\end{array}$ & $\begin{array}{l}70 \\
61\end{array}$ & $\begin{array}{r}4 \cdot 63 \\
71 \cdot 23\end{array}$ & $\begin{array}{l}0 \cdot 55 \\
0 \cdot 07\end{array}$ & $\begin{array}{l}7 \cdot 43 \\
0 \cdot 08\end{array}$ & $\begin{array}{r}0 \cdot 70 \\
11 \cdot 40\end{array}$ & $\begin{array}{l}0.98 \\
0.12\end{array}$ & $\begin{array}{l}1 \cdot 11 \\
0 \cdot 01\end{array}$ \\
\hline $\mathrm{M} 25$ & $\begin{array}{l}\text { Proline } \\
\text { Proline }+ \text { lysine }\end{array}$ & $\begin{array}{l}70 \\
80\end{array}$ & $\begin{array}{r}5 \cdot 02 \\
15 \cdot 67\end{array}$ & $\begin{array}{l}0 \cdot 19 \\
0 \cdot 01\end{array}$ & $\begin{array}{l}1 \cdot 93 \\
0 \cdot 20\end{array}$ & $\begin{array}{l}0.67 \\
1.91\end{array}$ & $\begin{array}{l}0.31 \\
0.01\end{array}$ & $\begin{array}{l}0 \cdot 26 \\
0 \cdot 02\end{array}$ \\
\hline M58 & $\begin{array}{l}\text { Proline } \\
\text { Proline }+ \text { arginine } \\
\text { Proline }+ \text { arginine }+ \\
\text { lysine }+ \text { histidine }\end{array}$ & $\begin{array}{l}60 \\
60 \\
60\end{array}$ & $\begin{array}{l}8 \cdot 90 \\
0 \cdot 78 \\
5 \cdot 33\end{array}$ & $\begin{array}{l}0 \cdot 29 \\
0 \cdot 05 \\
6 \cdot 61\end{array}$ & $\begin{array}{r}2 \cdot 16 \\
26 \cdot 91 \\
61 \cdot 63\end{array}$ & $\begin{array}{l}1 \cdot 39 \\
0 \cdot 13 \\
0 \cdot 87\end{array}$ & $\begin{array}{r}0.54 \\
0.09 \\
12 \cdot 74\end{array}$ & $\begin{array}{l}0 \cdot 33 \\
4 \cdot 31 \\
9 \cdot 94\end{array}$ \\
\hline M399 & $\begin{array}{l}\text { Allantoin } \\
\text { Allantoin + ornithine }\end{array}$ & $\begin{array}{l}75 \\
50\end{array}$ & $\begin{array}{c}6 \cdot 75 \\
46 \cdot 67 \dagger\end{array}$ & $\begin{array}{l}0.63 \\
0.07\end{array}$ & $\begin{array}{l}6 \cdot 44 \\
1 \cdot 72\end{array}$ & $\begin{array}{l}0.85 \\
8 \cdot 48 \dagger\end{array}$ & $\begin{array}{l}0.95 \\
0 \cdot 16\end{array}$ & $\begin{array}{l}0 \cdot 81 \\
0 \cdot 33\end{array}$ \\
\hline
\end{tabular}

* Since cells markedly enlarged after addition of a basic amino acid to the medium, normalization of the intracellular amino acid levels on the basis of total cell number did not seem appropriate. Therefore, normalization was made on the basis of total cell volume, which is proportional to light scattering or the observed Klett units. All concentrations were normalized to those observed in a $250 \mathrm{ml}$ culture of strain M 25 grown to a density of 70 Klett units in untreated glucose/ammonia medium.

$\dagger$ These values are the sum of the lysine and ornithine concentrations because it was not possible to separate these two amino acids by our procedures.

\section{Physiological basis of basic amino acid inhibition of growth}

Since ornithine can be converted to spermidine and other polyamines, it was possible that inhibition of growth was not caused by accumulation of basic amino acids, but rather by accumulation of or starvation for polyamines. Three experimental observations eliminated these hypotheses. First, basic amino acid inhibition of growth was not prevented by addition of putrescine, spermidine or spermine to the culture medium together with a basic amino acid. On the contrary, spermine was itself inhibitory at concentrations as low as $0.05 \mathrm{~mm}$. Second, the arginine analogue, homoarginine, inhibited growth of a wild-type culture provided with proline as sole nitrogen source (Fig. 1 a). Here, polyamine production was not possible, because Whitney \& Magasanik (1973) have demonstrated that homoarginine accumulated by a wild-type strain of $S$. cerevisiae may be quantitatively recovered in an unmodified form. Finally, polyamines were extracted from cultures grown in the presence or absence of basic amino acids and their total intracellular concentrations were determined. For these determinations, wild-type cells were grown with allantoin as sole nitrogen source in the presence or absence of lysine. Similarly a car2 mutant strain provided with allantoin was grown in the presence or absence of added ornithine. The relative levels of spermidine and spermine found in the test and control cultures differed less than twofold. 

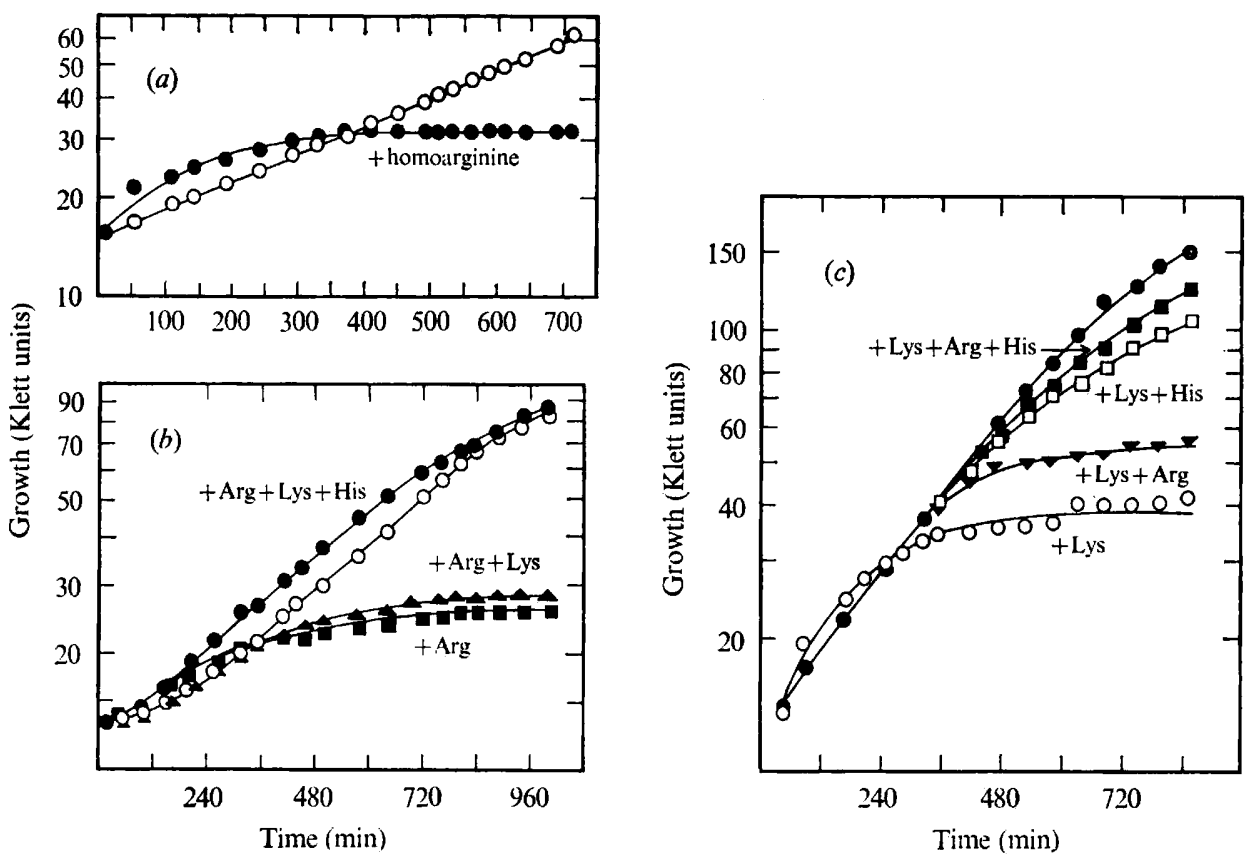

Fig. 1. Effect of basic amino acids on the growth of $S$. cerevisiae. The amino acids were added to give final concentrations of $2.5 \mathrm{~mm}$, except histidine was used at $0.5 \mathrm{~mm}$. (a) Strain M 58 was grown in glucose/proline medium to a density of about $15 \mathrm{Klett}$ units. The culture was then divided and one half received homoarginine (0) while the other half was left untreated $(\bigcirc)$. (b) Strain M58 was grown as in $(a)$. Portions of the culture received arginine $(\boldsymbol{\square})$, arginine plus lysine $(\boldsymbol{\Delta})$, arginine plus lysine plus histidine $(0)$ or remained untreated $(\bigcirc)$. (c) Strain M399 was grown in glucose/ allantoin medium. Portions of the culture received lysine $(\bigcirc)$, lysine plus arginine $(\boldsymbol{\nabla})$, lysine plus histidine ( $\square$ ), lysine plus arginine plus histidine $(\boldsymbol{\square})$ or remained untreated $(\bullet)$ : in these experiments arginine was added at $0.1 \mathrm{~mm}$.

Inhibition resulting from addition of non-metabolizable basic amino acids raised the possibility that accumulated basic amino acids themselves were causing growth inhibition. Therefore, we measured the total intracellular concentrations of basic amino acids in cultures grown in several different media (Table 2). Addition of lysine to cultures provided with either good or poor nitrogen sources markedly decreased the intracellular levels of histidine and arginine. When arginine was added to cultures of arginase-deficient strains, their histidine and lysine levels decreased. Such losses, however, were not as great when a repressive nitrogen source like asparagine was tested. Ornithine addition resulted in a similar decrease of histidine and arginine levels. The effect of ornithine on lysine levels could not be ascertained, because these two basic amino acids could not be resolved with our chromatographic conditions. If lysine, histidine and arginine were all added simultaneously to the culture medium, the intracellular levels of all three basic amino acids remained high. A preliminary study of the remaining acidic and neutral amino acids suggested no significant changes were occurring after treatment with a basic amino acid.

These observations suggested that adding one basic amino acid to the medium resulted in starvation for the other two and hence cessation of growth. To test this possibility, we monitored growth of an arginase-deficient strain and an ornithine transaminase-deficient strain following addition of one or more basic amino acids to the culture medium. Addition of arginine or lysine plus arginine did not permit growth of strain M58 (carl) in glucose/proline medium (Fig. $1 b$ ). However, addition of all three basic amino acids resulted in normal growth. A similar result was observed with the car 2 mutant strain (Fig. 1c). By comparing Fig. 1(b) and (c), it can be seen that addition of histidine resulted in more reversal of basic amino acid inhibition than either lysine or arginine. 


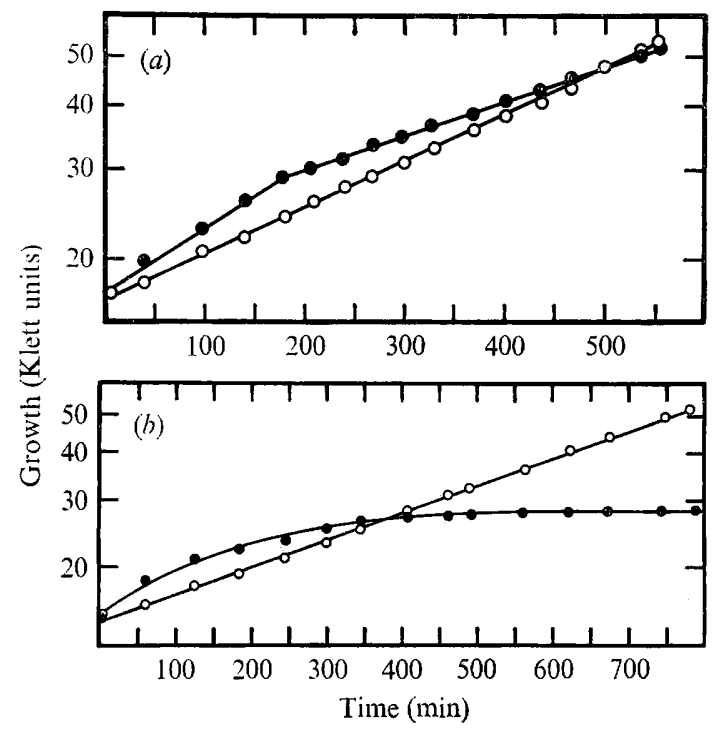

Fig. 2. Growth of the TRA3-1 mutant in the presence (O) or absence $(\bigcirc)$ of lysine. Haploid mutant strain DYA-150B ( $\alpha, T R A 3-1)$ was grown at $22^{\circ} \mathrm{C}$ in glucose/allantoin medium $(a)$ or glucose/ proline medium $(b)$ to a density of about $15 \mathrm{Klett}$ units. The cultures were then divided and lysine $(2.5 \mathrm{~mm}$ final concentration) was added to one half of each culture (zero time). Growth was measured turbidimetrically.

If the physiological basis of basic amino acid inhibition was a result of repressing amino acid synthesis, then strains in which amino acid biosynthesis was permanently and pleiotropically derepressed, because they carry mutated forms of a control element, should be resistant to inhibition. The TRA3-1 mutant originally isolated by Wolfner et al. (1975) possessed constitutively derepressed levels of enzymes for arginine, histidine, lysine and tryptophan biosynthesis even when histidine was added to the culture medium. This strain growing in glucose/allantoin medium was largely resistant to basic amino acid inhibition (see Fig. $2 a$ ), but remained sensitive when proline, an even poorer nitrogen source, was substituted for allantoin.

Basic amino acid inhibition of cultures growing slowly on poor nitrogen sources raised two possibilities. Inhibition might have occurred in cultures that were not able to dilute out accumulated basic amino acids via cell division. Alternatively, the lack of inhibition when readily used nitrogen sources were provided may have been the result of their ability to repress production of the basic and general amino acid permeases (Grenson, 1973; Grenson \& Ho, 1972) responsible for uptake of these metabolites. To distinguish between these alternatives, two wild-type cultures of $S$. cerevisiae were grown in medium containing lactate and ammonia as sole carbon and nitrogen sources. Lysine was added to one of the cultures, while the second received no further additions. The growth rate observed in the presence or absence of lysine was the same. This suggests that the rate of culture growth had little influence on the extent of inhibition, because cells grown in lactate/ammonia medium doubled more slowly ( $250 \mathrm{~min}$ doubling time) than those grown in glucose/proline medium (200 min doubling time).

\section{Effects of basic amino acid accumulation on cell morphology}

Cultures grown overnight in glucose/allantoin medium containing $2.5 \mathrm{~mm}$-lysine were found arrested in the cell cycle with most cells being larger than normal and possessing one large bud (Fig. 3). The same behaviour was observed when a car 2 mutant strain was incubated in the presence of ornithine. Nuclear staining (Hartwell, 1970) revealed that nuclear 


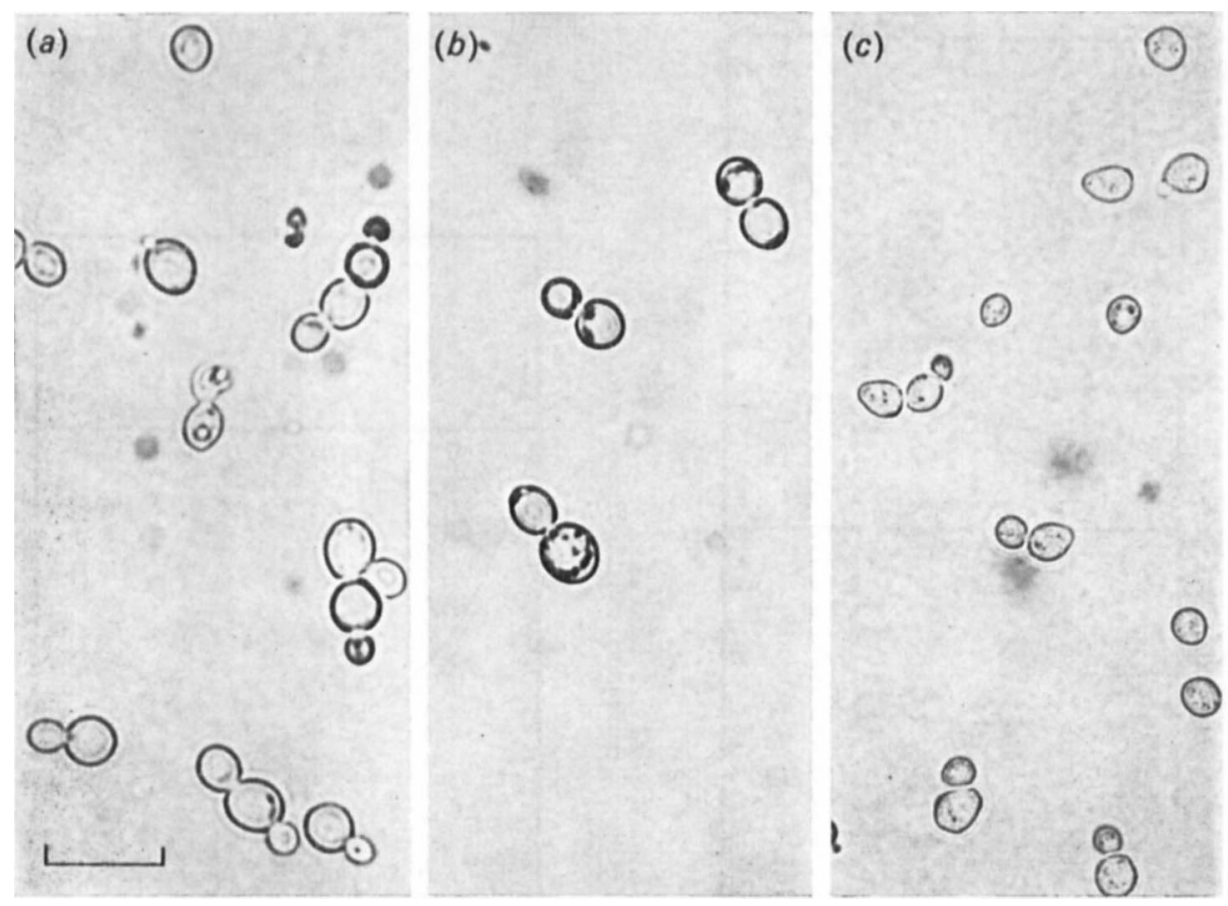

Fig. 3. Morphology of cells incubated in the presence or absence of basic amino acids. The car2 mutant $(a)$ or wild-type $(b, c)$ strains of $S$. cerevisiae were grown in glucose/allantoin medium to a density of $15 \mathrm{Klett}$ units. Ornithine $(a)$ or lysine $(b)$ was then added to a final concentration of $2.5 \mathrm{~mm}$, or the culture remained untreated $(c)$. After 400 min incubation, a sample of each culture was photographed with phase-contrast optics. Bar marker represents $20 \mu \mathrm{m}$.

division was completed in only a small minority of cases. Many cells had only one nucleus and in others the nucleus appeared as a dumb-bell shaped structure situated at the neck between mother and daughter cells. The time course of this phenomenon was followed by dividing a culture growing in glucose/allantoin medium into two portions and adding lysine to one of them. At various times after lysine addition, samples were removed from the culture and fixed with formalin for later observation. The turbidity of the culture continued to increase for about $300 \mathrm{~min}$ after addition of the amino acid. However, the increase in cell size noted above raised doubt that such measurements reflected an increase in cell number. These doubts were confirmed by counting the number of cells per unit volume of culture. Less than one cell division occurred in the $350 \mathrm{~min}$ following addition of lysine to the medium (Fig. $4 a$ ). As cells failed to divide, the ratio of budded to unbudded cells per unit volume increased more than fivefold (Fig. $4 b$ ). Similar results were observed with ornithine when strain M399 was used in place of the wild type. Inhibition of cell division was reversible (Fig. 5). Removal of lysine from the medium of a totally arrested culture resulted in increased turbidity (Fig. $5 a$ ) and a decrease in the ratio of budded to unbudded cells (Fig. $5 b$ ). However, if the period of lysine treatment was extended beyond $16 \mathrm{~h}$, reversal was impossible. It was also possible to reverse growth inhibition of cultures treated with ornithine. However, the degree of reversal was significantly less and required much more time.

The same effect on cell morphology was expected when proline was used in place of allantoin as nitrogen source. Cessation of the increase in turbidity followed the same time course observed with cultures grown in glucose/allantoin medium. Contrary to our expectation, however, no accumulation of budded cells was observed with this nitrogen source. In addition, it was not possible to reverse growth inhibition when basic amino acid-treated cultures were grown in glucose/proline medium. 


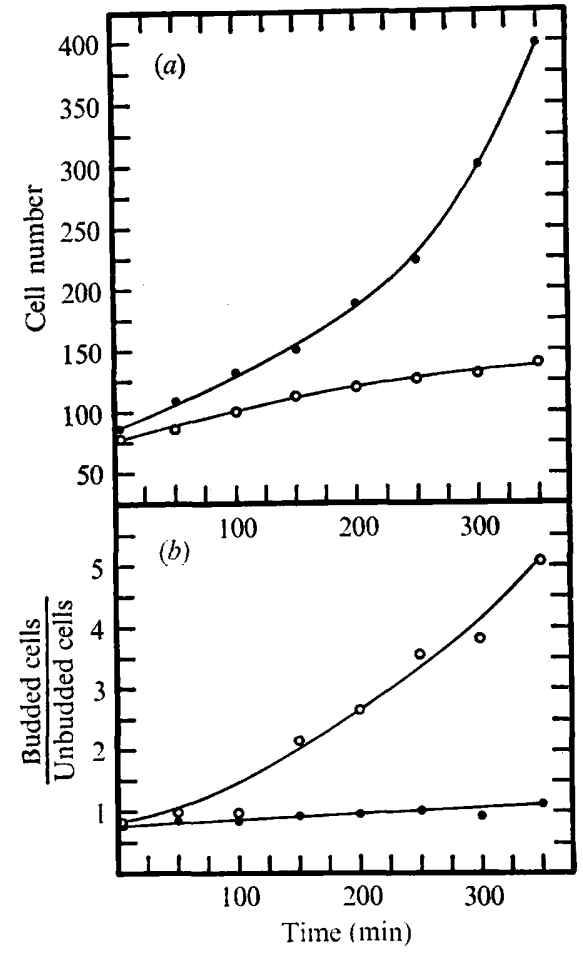

Fig. 4

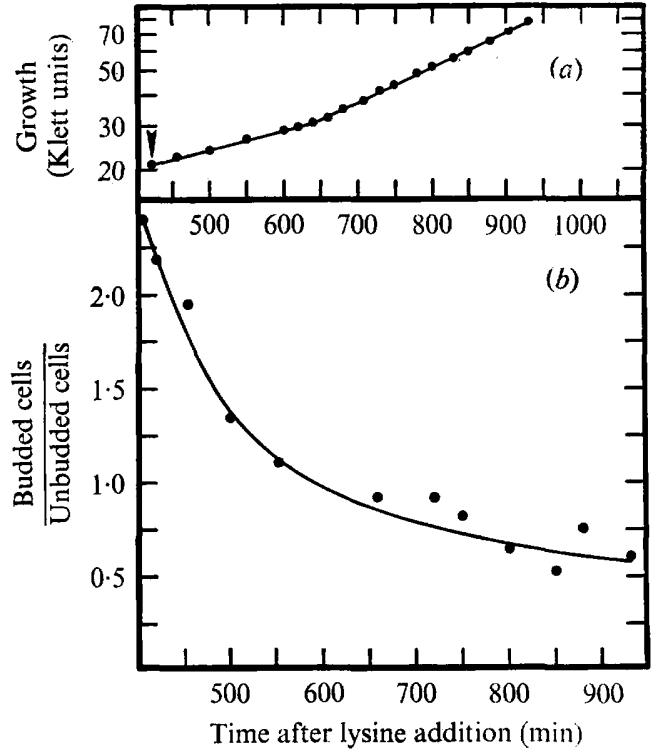

Fig. 5

Fig. 4. Effect of lysine on cell number and ratio of budded to unbudded cells. Strain M 25 was grown in glucose/allantoin medium to a density of $21 \mathrm{Klett}$ units. The culture was then divided and one half received lysine $(2.5 \mathrm{~mm})(\mathrm{O})$ while the other half remained untreated $(\bullet)$. At the times indicated, samples were removed for determination of cell number $(a)$ and morphology $(b)$.

Fig. 5. Reversal of basic amino acid growth inhibition in $S$. cerevisiae. Strain M25 was grown in glucose/allantoin medium to a density of $20 \mathrm{Klett}$ units. Lysine $(2.5 \mathrm{~mm}$ final concentration) was then added to the culture. After 400 min incubation, the cells were harvested by filtration and resuspended in an amount of pre-warmed, pre-aerated glucose/allantoin medium, devoid of lysine, sufficient to yield a density of 21 Klett units. Thereafter, turbidity of the culture $(a)$ and cell morphology $(b)$ were determined. Although not shown here, the cell number increased in parallel with culture turbidity.

\section{Effects of basic amino acid accumulation on macromolecular synthesis}

Arrest of cells with one large bud is reminiscent of the observations made by Hartwell (1974) in which this terminal phenotype was found when cells with temperature-sensitive defects in DNA synthesis were incubated at non-permissive temperatures. Similar behaviour has also been observed after treating cultures with $5 \mathrm{~mm}$-hydroxyurea, a known inhibitor of DNA synthesis (Slater, 1973). Therefore, we determined whether or not cells growing on poor nitrogen sources in the presence or absence of added basic amino acids could synthesize DNA. Addition of lysine to the wild-type strain grown in glucose/allantoin medium resulted in a pronounced loss of ability to synthesize DNA (Fig. 6a). This loss was even more dramatic when proline was used as sole nitrogen source (Fig. 6b). Similarly strong inhibition was observed when ornithine was added to car 2 mutant cultures instead of lysine (Fig. 6c,d).

Effects of basic amino acid accumulation on RNA and protein synthesis were determined by measuring incorporation of $\left[{ }^{3} \mathrm{H}\right]$ uracil and $\left[{ }^{3} \mathrm{H}\right]$ leucine respectively into TCA-precipitable material. Accumulation of basic amino acids did not seriously depress RNA synthesis (Table 3). Lysine addition also had only a minimal effect on protein synthesis when 

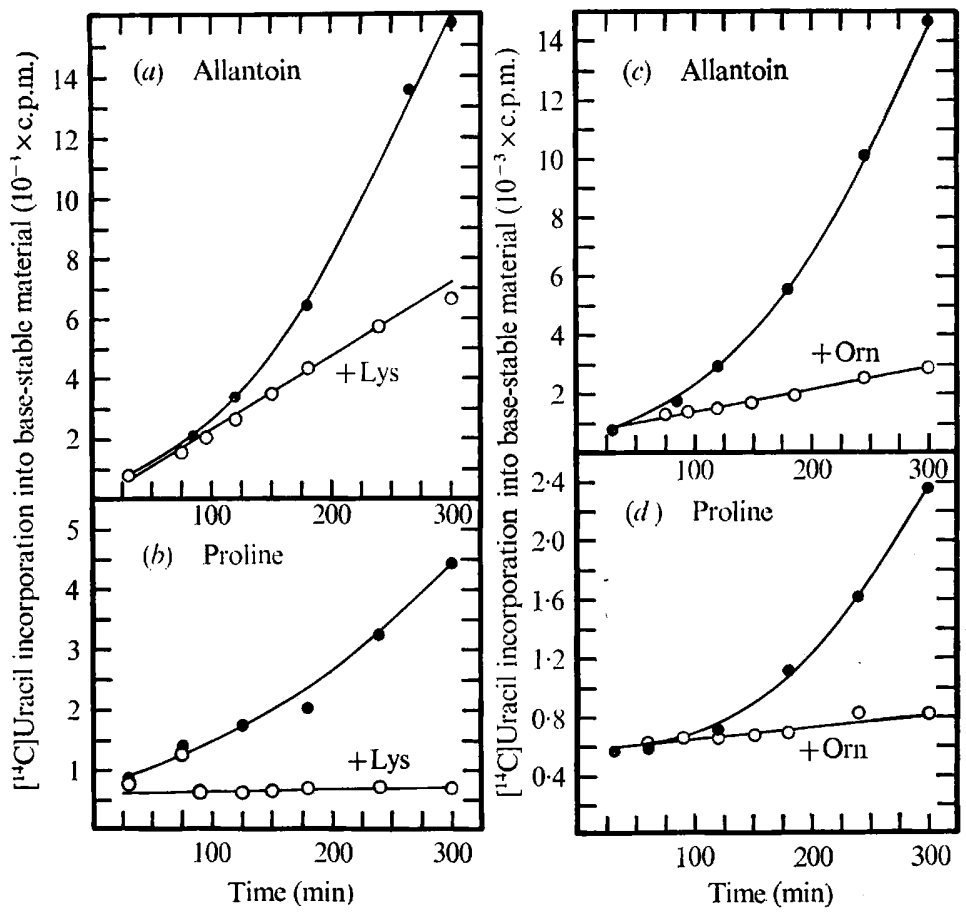

Fig. 6. Effect of basic amino acids on in vivo DNA synthesis. Wild-type (M25;a,b) or car2 mutant (M399; $c, d)$ strains were grown in glucose/allantoin medium $(a, c)$ or glucose/proline medium $(b, d)$ to densities of about $20 \mathrm{Klett}$ units. At zero time, $\left[{ }^{14} \mathrm{C}\right]$ uracil was added and $30 \mathrm{~min}$ later the cultures were divided. One half of each culture received either lysine $(a, b)$ or ornithine $(c, d)$ at final concentrations of $2.5 \mathrm{~mm}(O)$ while the remaining portions remained untreated $(\bullet)$ Thereafter, $1 \mathrm{ml}$ samples were transferred to test tubes containing $2 \mathrm{M}-\mathrm{NaOH}$ and processed as described in Methods. Base-stable, TCA-precipitable material comprised 4 to $6 \%$ of the total TCA-precipitable material.

Table 3. Rates of protein and RNA synthesis in wild-type (M25) and car2 mutant (M399) strains of $S$. cerevisiae grown in the presence or absence of basic amino acids

Strains M25 and M399 were grown in glucose/allantoin or glucose/proline medium to densities of about 20 Klett units. Each culture was then divided and one half received a basic amino acid $(2.5 \mathrm{~mm})$ while the other half remained untreated. At the same time, the radioactive precursor was also added. Samples were taken every 10 to $15 \mathrm{~min}$ and processed as described in Methods. Data are expressed as the amounts of radioactive material incorporated into TCA-precipitable material between 100 and $140 \mathrm{~min}$ incubation.

$\begin{array}{llcc}\text { Strain } & \text { Growth conditions } & \begin{array}{c}{\left[{ }^{3} \mathrm{H}\right] \text { Leucine }} \\ \text { incorporated } \\ \text { (c.p.m.) }\end{array} & \begin{array}{c}{\left[{ }^{3} \mathrm{H}\right] \text { Uracil }} \\ \text { incorporated } \\ \text { (c.p.m.) }\end{array} \\ \text { M25 } & \text { Allantoin } & 10600 & 5200 \\ & \text { Allantoin+lysine } & 9800 & 3000 \\ \text { M25 } & \text { Proline } & 6700 & 1300 \\ & \text { Proline+lysine } & 4600 & 1300 \\ \text { M399 } & \text { Allantoin } & 10500 & 2200 \\ & \text { Allantoin + ornithine } & 3400 & 1300 \\ \text { M399 } & \text { Proline } & 5700 & 700 \\ & \text { Proline +ornithine } & 1500 & 600\end{array}$


allantoin was used as the sole nitrogen source, but a stronger effect was observed with ornithine under these growth conditions. When either basic amino acid was added to cultures grown in glucose/proline medium, a significantly greater inhibition of protein synthesis occurred.

Although extensive analysis was not performed with cells growing in glucose/ammonia medium, DNA synthesis was assayed and found to be mildly decreased by addition of lysine and somewhat more strongly inhibited by addition of ornithine to the culture medium. A car 2 mutant was used in the latter experiment. These results suggest limited inhibitory effects occurred even under conditions where growth was not measurably inhibited.

\section{DISCUSSION}

Growth of S. cerevisiae on poor nitrogen sources was inhibited by addition of noncatabolized basic amino acids to the culture medium at concentrations normally used to fulfil auxotrophic requirements (18 to $53 \mu \mathrm{g} \mathrm{ml}^{-1}$ for lysine). Direct measurements of intracellular polyamine pools revealed that growth in the presence of basic amino acids did not significantly alter the amounts of these compounds. This makes it unlikely that growth inhibition was brought about by secondary production and accumulation of polyamines, although intracellular levels of basic amino acids themselves fluctuated drastically. Added lysine caused the levels of arginine and histidine to drop precipitously. Conversely, added arginine decreased lysine and hisidine levels 10 -fold. Therefore, inhibition of growth probably resulted from starvation for the basic amino acids that were not added to the medium. This conclusion is supported by the observation that when all three basic amino acids were provided in the medium, growth was normal. Histidine was probably the limiting species because the greatest reversal of inhibition was observed when this amino acid was provided in the medium.

The primary mechanism by which starvation was brought about remains obscure. It is quite likely that starvation resulted from a cessation of amino acid biosynthesis because our experiments were conducted with strains that were unable to degrade arginine, and lysine and histidine are normally not degraded by $S$. cerevisiae. This suggests that basic amino acid inhibition should not exist or at least be relieved in strains carrying the TRA3- 1 allele, since amino acid biosynthesis is permanently derepressed in organisms carrying this mutation. This was observed experimentally. It is intriguing, however, that even the effects of the TRA3-1 mutation were insufficient to prevent inhibition when very poor nitrogen sources such as proline were used.

The means by which basic amino acid starvation inhibits growth appears to be more complex than simply preventing gross protein synthesis. DNA synthesis was by far the most inhibited macromolecular synthetic process. When proline was provided as nitrogen source, both lysine and ornithine addition completely inhibited $\left[2-{ }^{14} \mathrm{C}\right]$ uracil incorporation into base-stable, TCA-precipitable material. Protein synthesis was variably depressed, ranging from almost no inhibition when cells were grown in glucose/allantoin medium containing lysine, to 30 to $70 \%$ loss when glucose/proline medium was used instead. This is somewhat surprising since starvation for an amino acid would be expected to decrease gross protein synthesis prior to any effects on DNA synthesis which may be observed. Losses observed especially with medium containing allantoin are insufficient to effectively terminate cell growth unless production of specific vital protein species were selectively lost. Histones, for example, contain large amounts of basic amino acids and might be just such species.

The differential loss of protein synthesis in cells using proline as compared to allantoin may offer an explanation as to why cells growing in allantoin medium accumulated as budded cells whereas those growing in proline medium did not. Cells using allantoin were able to carry out protein synthesis almost normally and hence could proceed through the cell cycle until they required DNA synthesis. However, the severely depleted pool of basic amino 
acids might not have been able to support sufficient synthesis of a specific protein needed for DNA synthesis. The lack of DNA synthesis might have been a secondary manifestation of basic amino acid imbalance. Cells growing in glucose/proline medium lost most of their ability to carry out protein synthesis and hence could not complete their cell cycles. Therefore, they did not collect as cells with one large bud. In effect, the use of various nitrogen sources might provide a means of titrating the loss of specific macromolecular biosynthetic processes.

The above otservations perhaps explain the earlier reports of Bourgeois \& Thouvenot (1970) who observed that lysine inhibited growth of an arginine auxotroph provided with low concentrations of arginine; no inhibition was observed at higher concentrations $(0 \cdot 6 \mathrm{~mm})$. At low concentrations of arginine, growth was probably inhibited in two ways: lysine competed with arginine for uptake and accumulated in the cell causing inhibition of post-exponential growth. At a higher concentration, arginine was capable of both fulfilling the auxotrophic requirement and serving as a supplemental nitrogen source. The presence of both arginine and ammonia as nitrogen sources would be quite sufficient to maintain some repression of lysine uptake. These investigators also observed a four to sixfold increase of arginase and ornithine transaminase levels when lysine was added. It is quite likely that lysine, on entering the cell, displaced arginine from the vacuole (unpublished observations). The released arginine could then induce arginase and ornithine transaminase. In agreement with this suggestion, Whitney \& Magasanik (1973) observed mild induction of arginase when ornithine, citrulline or lysine was added to the medium of wild-type cultures growing in glucose/ammonia medium. Under these growth conditions, basic amino acids would not be expected to inhibit growth, but displacement of one vacuolar component by another could easily occur.

Ramos et al. (1970 have reported that a strain of S. cerevisiae carrying two regulatory mutations $(\arg R$ and $c p a O)$ was unable to grow in glucose/glutamate medium containing ornithine. Since strains mutated in the $\arg R$ locus are known to lack ornithine transaminase activity (Wiame, 1971), it is possible that their observations result from the same physiological circumstances discussed in this report.

The authors wish to thank Dr Patricia Whitney for critically reviewing this manuscript, Dr Gerald Fink for providing the TRA3-1 mutant strain and Caroline Jorstad and Dr William Brown for performing the analyses of polyamine and amino acid pools respectively. This work was supported by Public Health Service Grants, GM-19386 and GM-20693, from the National Institute of General Medical Sciences. R.S. was supported by a graduate training grant, GM-000149, and T.G.C. was recipient of a Research Career Development Award, KO4-GM-00091.

\section{REFERENCES}

BourgeoIs, C. (1969). Influence de la lysine sur la croissance de Sacharomyces cerevisiae. Bulletin de la Société de chimie biologique 51, 935949.

Bourgeors, C. M. \& Thouvenot, D. R. (1970). Effets de la lysine sur la synthese et l'activite de l'arginase et de l'ornithone transaminase chez Saccharomyces cerevisiae. European Journal of Biochemistry 15, 140-145.

Cybis, J. \& Weglenski, P. (1969). Effects of lysine on arginine uptake and metabolism in Aspergillus nidulans. Molecular and General Genetics 104, 282-287.

Davis, R. H., LAwless, M. B. \& PoRT, L. A. (1970).
Arginaseless Neurospora: genetics, physiology and polyamine synthesis. Journal of Bacteriology 102, 299-305.

GRENSON, M. (1973). Specificity and regulation of the uptake and retention of amino acids and pyrimidines in yeast. In Genetics of Industrial Microorganisms, pp. 179-193. Edited by Z. Vanek, Z. Hostalek and J. Cudlin. Prague: Academia.

Grenson, M. \& Ho, C. (1972). Ammonia inhibition of the general amino acid permease and its suppression in NADPH-specific glutamate dehydrogenaseless mutants of Saccharomyces cerevisiae. Biochemical and Biophysical Research Communications 48, 749-756. 
Hartwell, L. H. (1970). Periodic density fluctuation during the yeast cell cycle and the selection of synchronous cultures. Journal of Bacteriology 104, 1280-1285.

HARTWELl, L. H. (1974). Saccharomyces cerevisiae cell cycle. Bacteriological Reviews 38, 164-198.

Hunter, A. \& Downs, C. E. (1945). The inhibition of arginase by amino acids. Journal of Biological Chemistry 157, 427-446.

Jenkins, W. T. \& TsaI, H. (1970). Ornithine aminotransferase (pig kidney). Methods in Enzymology 17A, 281-285.

MeISTER, A. (1965). The Biochemistry of Amino Acids, pp. 233-239. New York: Academic Press.

Morris, D. R., Koffron, K. L. \& OKstein, C. J. (1969). An automated method for polyamine analysis. Analytical Biochemistry 30, 449-453.

Pontecorvo, G. (1952). Genetic analysis or cell organisation. Symposia of the Society for Experimental Biology 6, 218-229.

Pontecorvo, G., Roper, J. A., Hemmons, L. M., MacDonald, R. D. \& Bufton, A. W. J. (1953). The genetics of Aspergillus nidulans. Advances in Genetics 5, 141-238.

Ramos, R., Thuriax, P., Wiame, J. M. \& Bechet, J. (1970). The participation of ornithine and citrulline in the regulation of arginine metabolism in Saccharomyces cerevisiae. European Journal of Biochemistry 12, 40-47.

SLATER, M. L. (1973). Effect of reversible inhibition of deoxyribonucleic acid synthesis on the yeast cell cycle. Journal of Bacteriology 113, 263-270.

Sumrada, R. \& CoOper, T. G. (1976). Basic amino acid inhibition of growth in Saccharomyces cerevisiae. Biochemical and Biophysical Research Communications 68, 598-602.

SumradA, R., Gorski, M. \& Cooper, T. G. (1976). Urea transport-defective strains of Saccharomyces cerevisiae. Journal of Bacteriology 125, 1048-1056.

WhitNey, P. A. \& CoOPER, T. G. (1972). Urea carboxylase and allophanate hydrolase. Two components of adenosine triphosphate:urea amidolyase in Saccharomyces cerevisiae. Journal of Biological Chemistry 247, 1349-1353.

Whitney, P. A. \& Magasanik, B. (1973). The induction of arginase in Saccharomyces cerevisiae. Journal of Biological Chemistry 248, 6197-6202.

WIAME, J. M. (1971). The regulation of arginine metabolism in Saccharomyces cerevisiae: exclusion mechanisms. In Current Topics in Cellular Regulation, vol. 4, pp. 1-38. Edited by B. L. Horecker and E. R. Stadtman. New York: Academic Press.

WiCKeRHAM, L. J. (1946). A critical evaluation of the nitrogen assimilation tests commonly used in the classification of yeasts. Journal of Bacteriology 52, 293-301.

Wolfner, M., Yep, D., Messenguy, F. \& FinK, G. (1975). Integration of amino acid biosynthesis into the cell cycle of $S$. cerevisiae. Journal of Molecular Biology 96, 273-290. 